\title{
DECIFRANDO A HISTÓRIA E O ESTIGMA DO ANALFABETISMO NO BRASIL
}

\author{
VALDEMAR SGUISSARDI ${ }^{*}$
}

\begin{abstract}
Para a concepção crítica, o analfabetismo não é uma "chaga", nem uma "erva daninha" a ser erradicada, nem tampouco uma enfermidade, mas uma das expressões concretas de uma realidade social injusta. (Freire apud Ferraro, 2009, p. 7)
\end{abstract}

A afirmação de Paulo Freire, em epígrafe, com que o autor, Alceu R. Ferraro, o homenageia na dedicatória deste livro - História inacabada do analfabetismo no Brasil -, sinaliza com ênfase que o leitor tem em mãos uma obra destinada a revolver as cinzas do passado para iluminar e clarear questões cruciais do presente neste campo: a construção social do analfabetismo como problema nacional; a emergência e configuração históricas das desigualdades regionais; a pretensa "pedagogia dos homens livres" da ditadura militar; a relação entre escola e produção do analfabetismo; e, por fim, a questão central: quem são os analfabetos?

Quando há alguns anos nascia, no âmbito do Conselho Editorial de Educação, da Editora Cortez, a proposta de constituição de uma Biblioteca Básica de História da Educação Brasileira (ввнев), esta foi pensada em duas séries. A primeira, para abordar temas como educação e escolarização, conforme registros cronológicos e temáticos amplos: educação no império; formação e difusão da escola republicana; disseminação da escola de massas a partir de 1920 ao final do século xx, entre outros. A segunda, para tratar de temas mais específicos, como a história da profissão docente no Brasil, história dos currículos, dos métodos e materiais de ensino. Dentre estes, logo se destacou o do analfabetismo no Brasil e sua história. E para abordá-lo, como ocorreu em outros casos, formou-se de imediato um claro consenso entre os membros desse Conselho Editorial e coordenadores dessa Biblioteca Básica: a "encomenda" deveria ser feita primeiramente a um determinado especialista de renome na área. A alguém que há muito alimentava, com raro domínio da matéria, o debate

\footnotetext{
* Resenha do livro de Alceu Ravanello Ferraro, História inacabada do analfabetismo no Brasil (São Paulo: Cortez; ввнев, 2009).

** Doutor em Ciências da Educação e professor titular aposentado da Universidade Federal de São Carlos (UfSCAR).E-mail: vs@merconet.com.br
} 
de um tema ainda insuficientemente estudado e cuja compreensão se tornava a cada dia mais vital para a história, não apenas da educação, mas também da cultura política do país como nação.

Ferraro relata, na introdução deste livro, o desafio que lhe significou esse convite e dele faz o ponto de partida de uma oportuna e pertinente reflexão sobre algumas questões metodológicas postas para um sociólogo convidado a tratar da história do analfabetismo no Brasil. Tais questões se iniciam com a pergunta sobre quem são os historiadores da educação. A esta ele responde, com apoio em conclusões de estudo de Clarice Nunes, que são "pedagogos, historiadores, filósofos e sociólogos da educação, entre outros profissionais, tratando-se, portanto, de pesquisadores com formação, perspectiva e interesses diferentes" (Ferraro, 2009, p. 12). Pesquisadores que interrogam, "além de fontes específicas, outras, de diferente natureza (econômicas, políticas, por exemplo), a partir das exigências próprias dos fenômenos pedagógicos e/ou educativos" (Nunes apud Ferraro, op. cit., p. 12).

Suas preocupações metodológicas o levam a examinar as relações, muitas vezes conflituosas, entre sociólogos e historiadores na abordagem de múltiplos temas, mas que encontrariam na maioria dos casos, como o do objeto deste estudo, razões de frutífera colaboração e rica complementaridade; mormente quando se adota, para perspectivas históricas de mudança, a do tipo "definido como sendo o das mudanças ou processos de longa duração (alfabetização, escolarização, feminização do magistério) que tiveram lugar no decorrer dos séculos XIX e xx e que, todavia, continuam inacabados na entrada do século xxI" (Ferraro, op. cit., p. 13).

Como esclarece o autor, essa é exatamente a principal perspectiva de mudança que interessa neste estudo, isto é, a de mudanças de longa duração: “É nesse sentido, por exemplo, que se falará de tendência secular do analfabetismo. Mesmo quando se considere um período menor de tempo (algumas décadas, por exemplo), o olhar estará voltado para o longo prazo" (idem, ibid., p. 14).

Essa é a perspectiva que lhe dará amparo na decisão de tomar como ponto de partida desta história não a década de 1930, como lhe fora solicitado pelos organizadores da ввнЕв, mas o ano de 1872, ano em que se realizou o primeiro recenseamento geral da população no Brasil.

O autor vai mais além nessas precisões metodológicas que dão a esta obra a solidez de um clássico. Faz, entre outras, uma consistente discussão acerca da relação entre perspectivas quantitativas e qualitativas em estudo desta natureza. Chama especialmente a atenção para os limites daquelas, tratando as estatísticas, por exemplo, "como objeto de investigação, de questionamento, e não simplesmente como algo dado" (p. 15). 
Além dessa consistente introdução, que alerta o leitor para a riqueza e os desafios teórico-metodológicos do conteúdo da obra, esta se compõe de oito capítulos com variados enfoques e espaços cronológicos. ${ }^{1}$

No primeiro capítulo - "Analfabetismo no Brasil na entrada do século xxI" - o autor nos faz ver o quanto a história do analfabetismo continua inacabada e quão desafiante e imensa é a tarefa de alfabetização que ainda sobra para o nosso século.

Com esse ponto de partida, no segundo capítulo - "Analfabetismo no Brasil: um retrospecto" - faz-se uma necessária retomada da questão do analfabetismo, com destaque para três pontos, segundo o autor: "explicitação de algumas posições contrastantes dentro do próprio liberalismo quanto à alfabetização e escolarização das massas"; "descrição do estado educacional no Segundo Reinado"; e "busca de um ponto de partida para a história do analfabetismo" sobre o qual se propôs a escrever (Ferraro, op. cit., p. 16).

Um dos capítulos centrais deste livro, especialmente para não versados em importantes eventos e subperíodos do Segundo Reinado, é o terceiro - "A construção social do analfabetismo como questão nacional: 1878-1881" -, que trata exatamente da relação desta construção social com os debates, na Câmara dos Deputados, em torno dos projetos liberais da reforma eleitoral ocorridos nesse período. Visavase então a aprovação da Lei Saraiva, de 9 de janeiro de 1881, "que incluiu na legislação e na prática política a exclusão dos analfabetos do direito de voto" (idem, ibid., p. 17). Como diz o autor (idem), "Mostro, com base nos debates parlamentares, como os termos analfabetismo e analfabeto foram transformados em verdadeiro estigma, e como o problema do analfabetismo, de questão pedagógica, se transformou numa questão eminentemente ideológica". Esta demonstração se configura, ao lado da resposta à questão sobre quem são os analfabetos, no, talvez, principal legado desta obra.

O quarto capítulo - “Trajetória do analfabetismo no Brasil: 1872 a 2000" - é onde se colocam questões como a da periodização da trajetória do analfabetismo nesse longo período, do primeiro ao seu mais recente censo, e, metodológicas, como a relacionada ao Censo de 1900.

Para marcar um dos momentos centrais em que afloram as verdadeiras contradições do pensamento, cultura e política dominantes em relação ao analfabeto e ao analfabetismo no Brasil, o autor insere como quinto capítulo um estudo anterior que ele elaborou e publicou na década de 1980, mas que apresenta a mais flagrante atualidade: “мовral: a 'pedagogia dos homens livres' da Ditadura Militar".

Em "Analfabetismo no Brasil: configuração e gênese das desigualdades regionais", como sexto capítulo, ao mesmo tempo em que Ferraro retoma a questão da 
trajetória do analfabetismo, o faz sob o ângulo da sua dimensão regional. Aqui se tornam evidentes os traços da construção também social das desigualdades regionais em que o analfabetismo emerge como um exemplo marcante.

No sétimo capítulo - "Quem são os analfabetos? Cruzando as perspectivas de classe, raça, gênero e geração" - enfoca-se, ao lado do que tratou da construção social do analfabetismo, um dos dois pilares essenciais deste estudo. Aqui se dá o coroamento das análises e reflexões que já despontavam no primeiro capítulo e que, de variadas formas, perpassam todos os capítulos anteriores. Como diz o autor, esta pergunta "requer atenção especial, até porque ela leva inapelavelmente a que o pesquisador se pergunte sobre o porquê das desigualdades quanto à alfabetização, provenham estas das relações étnico-raciais, de classe social ou de gênero ou resultem elas de qualquer combinação dessas três dimensões" (Ferraro, 2009, p. 144).

O autor encerra seu livro com o oitavo capítulo - "Escola e produção do analfabetismo no Brasil: 1970-2005" -, no qual retoma uma velha questão com que tem trabalhado nos anos de 1980, que visa mostrar "quanto e como a reprodução persistente do analfabetismo nas novas gerações tem a ver com a dupla forma de exclusão escolar: a exclusão da escola e a exclusão na escola" (idem, ibid., p. 18).

Falando da escola que exclui, o autor retoma uma significativa frase de um seu estudo anterior que dizia: "a escola é tanto mais excludente quanto mais o é a sociedade à qual serve" (idem, p. 189). Parodiando, algo similar se poderia dizer do analfabetismo, isto é, que ele é tanto mais um símbolo de desigualdade e injustiça sociais quanto mais desigual e injusta se apresenta a sociedade que o produz e realimenta.

A leitura deste livro, estruturado com capítulos bastante autônomos, mas, ao mesmo tempo, com estreitos traços empíricos e interpretativos interligando-os de modo orgânico (ver nota 1), produzirá no leitor muitos sentimentos. Dentre estes, alguns poderiam aqui se destacar. O primeiro é o de admiração pelo domínio do tema abordado e das exigências teórico-metodológicas que seu tratamento exige. O segundo, o do prazer estético provocado pelo estilo de redação que demonstra completo domínio da lógica da expressão escrita, da precisão da linguagem, sem sofisticação, o que possibilita a compreensão do exposto por leitores de diferentes níveis de iniciação ao tema. O terceiro sentimento é o da importância de um estudo desta natureza, com esta profundidade, como instrumento na luta obrigatória pela destruição das condições estruturais do "modelo" de desenvolvimento que produz e realimenta o analfabetismo como realidade crônica deste país.

Dentre os onze pontos destacados pelo autor, como síntese provisória deste livro, na conclusão de seu último capítulo, que trata da relação entre escola e analfabetismo, vale a pena transcrever o que visa enfatizar o papel da escola na sua produção: “Não basta superar a exclusão da escola mediante a expansão e até a 
universalização do acesso. Importa transformar a lógica de exclusão que historicamente veio regendo o processo de escolarização das camadas populares" (Ferraro, 2009, p. 195).

O domínio sobre a história do analfabetismo no Brasil - ainda que inacabada, porque o próprio fenômeno em estudo, como diz o autor, tem um fim imprevisível - dá, com este livro, passos firmes, qualificados e também norteadores das tarefas que especialistas, estudiosos e militantes devem continuar a enfrentar neste campo repleto de desafios longevos e persistentes. ${ }^{2}$

\section{Notas}

1. Em relação à forma de organização do livro, destaca o autor - e o leitor poderá comprová-lo - que, embora tenha sido composto de um conjunto de capítulos relativamente autônomos - "cada um deles poderia ser lido e compreendido independentemente do demais" -, eles mantêm laços muito estreitos, interligando-os de forma bastante harmônica.

2. Como é praxe nos livros da Biblioteca Básica de História da Educação Brasileira (ввнев) a que pertence, este volume traz, ao final, como sugestão de leitura para aprofundamento do tema, nove obras selecionadas e comentadas pelo autor. 